\title{
Visualising catchment-scale spatio-temporal dynamics of storage-flux-age interactions using a tracer-aided ecohydrological model
}

\author{
Aaron Smith ${ }^{1}$, Doerthe Tetzlaff ${ }^{2}$, Marco Maneta ${ }^{3}$, and Chris Soulsby ${ }^{2}$ \\ ${ }^{1}$ Leibniz Institute of Freshwater Ecology and Inland Fisheries \\ ${ }^{2}$ University of Aberdeen \\ ${ }^{3}$ University of Montana
}

September 25, 2021

Aaron Smith $^{1}$, Doerthe Tetzlaff ${ }^{1,2,3}$, Marco Maneta ${ }^{4}$, Chris Soulsby $^{3,2}$

${ }^{1}$ IGB Leibniz Institute of Freshwater Ecology and Inland Fisheries Berlin, Berlin, Germany

${ }^{2}$ Humboldt University Berlin, Berlin, Germany

${ }^{3}$ Northern Rivers Institute, School of Geosciences, University of Aberdeen, UK

${ }^{4}$ Department of Geosciences, University of Montana, Missoula, Montana, USA

Correspondence to: Aaron Smith (smith@igb-berlin.de)

\section{Description}

Quantifying catchment-scale water cycling over longer periods is important as wet and dry precipitation cycles can adversely affect blue (groundwater and discharge) and green (evapotranspiration) water fluxes and storage dynamics (Orth \& Destouni, 2018; Yang, Tetzlaff, Soulsby, Smith, \& Borchardt, 2021). Spatially distributed modelling approaches are, in many circumstances, essential for spatio-temporal evaluation of the non-stationarity of flow paths and storages within catchments (Fatichi et al., 2016). When linked with tracers and water age tracking such models can also aid in understanding the ecohydrological separation of water sources (McGuire \& McDonnell, 2015). Here, we present a visualisation of results from a traceraided ecohydrological model to explore spatiotemporal dynamics of water flux-storage-tracer-age interactions through wet and extreme dry (including the European 2018 drought) cycles. This visualisation extends beyond the traditional "snapshot" of spatial catchment conditions or temporal depiction of a single "point", providing further novel understanding of spatial differences in catchment response and interactions under wet and dry conditions.

$\mathrm{EcH}_{2} \mathrm{O}$-iso is a tracer-aided ecohydrological model coupling vegetation-soil-atmosphere energy, water, and tracer mass-balance with a simultaneous solution of vegetation dynamics and water age (Kuppel, Tetzlaff, Maneta, \& Soulsby, 2018; Maneta \& Silverman, 2013). Energy and water balance are estimated with a topdown approach from the canopy to the sub-surface. The energy balance is solved iteratively for temperature (canopy and surface) to estimate latent, sensible, and ground heat, soil temperatures, and net radiation. Water balance is solved in five model storages: canopy, surface, and soil (three storage layers) with vertical movement through all storages, and lateral movement (kinematic wave) in surface and deep soil water. 
Evapotranspiration components are derived from the energy balance. Water ages and isotopic tracers are estimated in each storage with complete mixing. The Demnitzer Millcreek catchment (DMC, $\left.66 \mathrm{~km}^{2}\right)$ is a mixed-landuse mesoscale catchment in north-east Germany, representative of other catchments in the North European Plain. The DMC has annual mean precipitation and discharge of 560 and $60 \mathrm{~mm}$, respectively with stream flow being groundwater-dominated (Smith, Tetzlaff, Gelbrecht, Kleine, \& Soulsby, 2020; Smith, Tetzlaff, Kleine, Maneta, \& Soulsby, 2021). Four major landuse units are distinguishable: agricultural, coniferous forest, wetlands, and broadleaf forest. The soils are primarily sandy brown earths, with peaty podzolic soils in wetlands and gley beneath the channels. Discharge and stream chemistry time-series (1990 - present) and soil moisture, sap flow, soil and discharge isotopes (2018-present) have been monitored in the main channel and primary landuses (Gelbrecht, Lengsfeld, Pöthig, \& Opitz, 2005; Smith et al., 2021). $\mathrm{EcH}_{2} \mathrm{O}$-iso was set up on $250 \mathrm{~m}$ square grids for the DMC and simulated on daily time-steps from 2007-2019 using the first two years as spin-up. Multi-criteria calibration utilized available data to constrain soil storage, ecohydrological fluxes, and isotopic tracers in the primary landuses (nine soil and six vegetation parameters for each landuse, Smith et al., 2021).

The visualisation (Movie 1) shows the bi-weekly spatial and average changes in catchment storage (in shallow soil and groundwater), transpiration, specific discharge, transpiration and discharge age, and tracer dynamics (shallow soil and discharge) over an extended period from 2009-2019 to provide novel insights of spatially disaggregated catchment interactions in wet and dry periods. The bottom left panel shows the profile of catchment landuse for context, with agriculture dominant in the north, wetlands in the central catchment and forests in the south. To aid in spatial visualisation, the scales are set to the $5^{\text {th }}$ and $95^{\text {th }}$ percentiles of monthly averages, with a log-scale for the transpiration ages. Low precipitation toward the end of the study period caused a long-term decrease in groundwater (meters of water above field capacity) and summer soil water storage and an increase in transpiration age.

Relationships of catchment wetness to storage, fluxes, tracers, and ages were temporally consistent; however, the strength of these relationships changes seasonally. Higher wetness conditions during the early and mid growing season (0:07 \& 0:21) decreased total catchment transpiration relative to drier years $(0: 39 \&$ 0:43) due to lower atmospheric vapour pressure deficit in wet conditions. Wetter conditions additionally increased soil water fractionation (higher $\delta^{2} \mathrm{H}$ ) during the early and mid-growing season due to increased soil evaporation. Late growing season wetness conditions did not strongly affect transpiration; however, wetter conditions in winter and higher rainfall years increased discharge and decrease water ages of transpiration and discharge (0:09 v. 0:57).

Spatio-temporal differences between wet and dry growing season months are primarily distinguishable by landuse. In particular, wetlands consistently had higher moisture and lower transpiration, while spatial differences between agricultural areas in the north and conifer forests in the south deviated with wetness conditions. Wet conditions in the early growing season reduced spatial differences of soil moisture (e.g. 0:26 v. 1:01), but resulted in larger spatial differences in stream water age (lower water age through the conifer areas), and decreased spatial differences in transpiration water age between conifers and agricultural areas. Spatial differences in soil moisture were not as prominent during the mid-growing season regardless of wetness conditions. However, wetter conditions in mid-summer drove greater spatial differences in transpiration and channel fractionation, and lower differences in transpiration age between conifers and agricultural landuse (e.g. 0:50 v. 0:38). Under these conditions, transpiration rates were higher in conifer forests, and more water available in shallow soils for transpiration spatially unified water ages throughout the catchment. Drier conditions resulted in lower transpiration in conifer forests compared to agricultural areas. Spatiotemporal variations during the late growing season showed further consistent trends with wetness, with greater spatial differences in transpiration and smaller spatial effects of channel fractionation under wetter conditions (0:15 v. 0:45).

Here, we explored the visualisation of spatio-temporal dynamics catchment fluxes, storages, tracers, and water ages through wet and dry periods in a mesoscale, mixed-landuse catchment in Germany. Spatial variation in transpiration, evaporative fractionation, water age and soil moisture are directly related to 
inter-annual variations of catchment wetness, with additional intra-annual spatial variability within the growing season. These visualisations of storage-flux-age dynamics aid in the understanding of the sensitivity of key catchment regions and could improve knowledge of hydrological catchment functioning in wet and dry conditions under long-term change. As such, they are useful tools to communicate the output of complex ecohydrological models to land managers.

\section{References}

Fatichi, S., Vivoni, E. R., Ogden, F. L., Ivanov, V. Y., Mirus, B., Gochis, D., . . . Tarboton, D. (2016). An overview of current applications, challenges, and future trends in distributed process-based models in hydrology. Journal of Hydrology, 537 , 45-60. doi:https://doi.org/10.1016/j.jhydrol.2016.03.026

Gelbrecht, J., Lengsfeld, H., Pöthig, R., \& Opitz, D. (2005). Temporal and spatial variation of phosphorus input, retention and loss in a small catchment of NE Germany. Journal of Hydrology, 304 (1-4), 151-165. doi:10.1016/j.jhydrol.2004.07.028

Kuppel, S., Tetzlaff, D., Maneta, M. P., \& Soulsby, C. (2018). EcH2O-iso 1.0: water isotopes and age tracking in a process-based, distributed ecohydrological model. Geoscientific Model Development, 11 (7), 3045-3069. doi:10.5194/gmd-11-3045-2018

Maneta, M. P., \& Silverman, N. L. (2013). A Spatially Distributed Model to Simulate Water, Energy, and Vegetation Dynamics Using Information from Regional Climate Models. Earth Interactions, 17 (11), 1-44. doi:10.1175/2012ei000472.1

McGuire, K. J., \& McDonnell, J. J. (2015). Tracer advances in catchment hydrology. Hydrological Processes, 29 (25), 5135-5138. doi:https://doi.org/10.1002/hyp.10740

Orth, R., \& Destouni, G. (2018). Drought reduces blue-water fluxes more strongly than green-water fluxes in Europe. Nat Commun, 9 (1), 3602. doi:10.1038/s41467-018-06013-7

Smith, A., Tetzlaff, D., Gelbrecht, J., Kleine, L., \& Soulsby, C. (2020). Riparian wetland rehabilitation and beaver re-colonization impacts on hydrological processes and water quality in a lowland agricultural catchment. Sci Total Environ, 699 , 134302. doi:10.1016/j.scitotenv.2019.134302

Smith, A., Tetzlaff, D., Kleine, L., Maneta, M., \& Soulsby, C. (2021). Quantifying the effects of land use and model scale on water partitioning and water ages using tracer-aided ecohydrological models. Hydrology and Earth System Sciences, 25 (4), 2239-2259. doi:10.5194/hess-25-2239-2021

Yang, X., Tetzlaff, D., Soulsby, C., Smith, A., \& Borchardt, D. (2021). Catchment Functioning Under Prolonged Drought Stress: Tracer-Aided Ecohydrological Modeling in an Intensively Managed Agricultural Catchment. Water Resources Research, 57 (3), e2020WR029094. doi:https://doi.org/10.1029/2020WR029094 